Previous studies have focused predominantly on selection alone rather than on selection with enrichment. As for other bacterial searches, it would be expected that some form of selective enrichment should perform the best. The stringency of search for $B$ cepacia is, of course, the driving force for the need for selective or enrichment techniques. For the purposes of antimicrobial chemotherapy, the finding of lesser quantities of $B$ cepacia compared to other pseudomonads may not alter a treatment regimen. In contrast, the belief that person to person transmission does occur with reasonable frequency has caused some to believe that absolute knowledge of carrier status is essential.

How should the carrier be defined and will all such carriers confer equal risk for transmission? If the simple identification of $B$ cepacia at any site, regardless of quantity, defines the carrier, how many samples (and from which sites) should be acquired? If a carrier is identified, what criteria should be present before the patient ceases to be classified as a carrier? Our experience with the finding of transient oropharyngeal carriage despite the use of selective enrichment in one patient is a good example of a circumstance where the above dilemmas need to be resolved. Transient carriage of $B$ cepacia after acquisition from summer camp exposure is known to occur. Although it is sensible to observe good personal and interpersonal hygiene so that respiratory pathogens in general, let alone $B$ cepacia, are not transmitted, the strict definition of a carrier and the social segregation that can arise, may not always be in the best interests of the patient. Studies which examine these issues may be better served by the use of selective enrichment media.

1 Tablan OC, Martone WJ, Doershuk CF, et al. Colonization of the respiratory tract with Pseudomonas cepacia in cystic f

2 Isles A, Maclusky M, Corey R, et al. Pseudomonas cepacia infections in cystic fibrosis; an emerging problem. $\mathcal{F}$ Pediatr infections in cystic

3 Snell GI, DeHoyos A, Krajden M, Winter T, Maurer JR Pseudomonas cepacia in lung transplant recipients with cystic fibrosis. Chest 1993;103:466-71.

4 Govan JRW, Brown PH, Maddison J, et al. Evidence for transmission of Pseudomonas cepacia by social contact in cystic fibrosis. Lancet 1993;342:15-19.

5 Welch DF, Muszynski MJ, Pai CH, et al. Selective and differential medium for recovery of Pseudomonas cepacia from the respiratory tracts of patients with cystic fibrosis. 7 Clin Microbiol 1987;25:1730-4.

6 Gilligan PH, Gage PA, Bradshaw LM, Schidlow DV, DeCicco BT. Isolation medium for the recovery of Pseudomonas cepacia from mistory secretions of patients with monas cepacia from respiratory secretions of

7 Black-Payne C, Lierl MB, Bocchini JA, Hilman BC, Rambin ED, Silberman R. Comparison of two selective media developed to isolate Pseudomonas cepacia from patients developed to isolate Pseudomonas cepacia from patients with cys

8 Carson LA, Tablan OC, Cusick LB, Jarvis WR, Favero MS, Bland LA. Comparative evaluation of selective media for isolation of Pseudomonas cepacia from cystic fibrosi patients and environmental sources. F Clin Microbiol 1988; 26:2096-100.

9 Tablan OC, Carson LA, Cusick LB, Bland LA, Martone WJ, Jarvis WR. Laboratory proficiency test results on use of selective media for isolating Pseudomonas cepacia from solating Pseudomonas cepacia from simulated sputum specimens of patients with cystic fib-

10 Wahba AH, Darrell JH. The identification of atypical strains of Pseudomonas aeruginosa. $\mathcal{F}$ Gen Microbiol 1965;38:329 42 .
Hepatitis and

Retrovirus Laboratory,

PHLS Virus Reference

Division,

Central Public

Health Laboratory,

61 Colindale Avenue,

London NW9 5HT

L McAlpine

J V Parry

P P Mortimer

Department of

Medical Microbiology,

Charing Cross and

Westminster Medical

School,

369 Fulham Road,

London

SW10 9NH

D Shanson

Correspondence to:

Dr P P Mortimer.

Accepted for publication

26 September 1994

L McAlpine, J V Parry, D Shanson, P P Mortimer

Abstract

The sensitivity of 12 commonly used antiHIV-1/HIV-2 enzyme immunoassays was evaluated. The assays, each of which utilises at least one synthetic HIV antigen, were tested against a panel of 1092 specimens previously designated anti-HIV positive. In a total of 13104 tests there were eight false negative results attributable to assay insensitivity: three were on two serum samples collected close to seroconversion and five on another serum specimen. These eight false negative results arose in seven different assays. Five other false results were attributable to technical error. This false negativity rate indicates that all of the assays performed adequately and leads to an estimate of one false negative result in a thousand tests in routine diagnostic practice. Because of the antigenic heterogeneity of HIV strains, similar evaluations would be required in several regions before this satisfactory level of sensitivity in anti-HIV assays incorporating synthetic antigens could be said to be universal.

(f Clin Pathol 1995;48:490-493)

Keywords: HIV screening, synthetic HIV antigens, false negative results. 
Table 1 The 12 anti-HIV-1/2 ELAs studied

\begin{tabular}{|c|c|c|c|}
\hline Assay No. & Assay name (Product No.) & $H I V-1$ antigen & $H I V-2$ antigen \\
\hline 1 & $\begin{array}{l}\text { Abbot recombinant HIV-1/HIV-2 3rd generation } \\
\text { (3A10-24) }\end{array}$ & Recombinant (gag and $e n v$ ) & Recombinant (env) \\
\hline 2 & Behring Enzygnost Anti-HIV-1/-HIV-2 (OWRP) & Peptide (gp41) & Peptide (gp36) \\
\hline 3 & Biochrom HIV-1/HIV-2 Elisa Version 2 (D 7651) & Peptide (gp41 and gp120) & Peptide (gp36) \\
\hline 4 & Biotest Anti-HIV-1/-2 Recombinant (807005) & Recombinant (p24 and gp41) & Recombinant (gp36) \\
\hline 5 & Diagnostics Pasteur Genelavia MIXT (72267) & Recombinant (gp160)/peptide (env) & Peptide $(e n v)$ \\
\hline 6 & IAF Biochem Detect HIV (851403) & Peptide & Peptide \\
\hline 7 & Innotest HIV-1/HIV-2 Ab (M422) & Recombinant ( $g a g$ and $e n v$ ) & Peptide $(e n v)$ \\
\hline 8 & Ortho HIV-1/HIV-2 ELISA (932010) & Virion/recombinant & Peptide $(e n v)$ \\
\hline 9 & Sorin ETI-AB-HIV K (P3076) & Recombinant (p24 and gp41) & Peptide (gp36) \\
\hline 10 & UBI HIV-1/2 EIA (6021) & Peptide $(e n v)$ & Peptide (env) \\
\hline 11 & Vironostika HIV MIXT (6005) & Virion & Peptide \\
\hline 12 & Wellcozyme HIV $1+2$ (VK 54) & Recombinant ( $g a g$ and $e n v$ ) & Peptide (env) \\
\hline
\end{tabular}

Though false positivity in anti-HIV assays has been extensively studied, little information exists on rates of false negativity. Even in circumstances where the incidence of infection is high, it is rare for more than one anti-HIV assay, or a HIV p24 antigen as well as an antiHIV assay, to be used and it is vital that the single anti-HIV assay chosen be adequately sensitive.

In recent years, anti-HIV assays based on purified viral lysate antigen have been superseded by assays employing recombinant DNA derived and oligopeptide antigens. ${ }^{12}$ These synthetic antigens are safe to manufacture and assays based on them have generally detected anti-HIV earlier in the course of HIV infection than the lysate antigens that they have replaced. ${ }^{1}$ They might, however, lack sufficient antigenic diversity to identify all individuals infected with HIV and in that sense be no more sensitive than assays based on native antigens. To test this hypothesis we took over 1000 reportedly anti-HIV positive serum specimens collected in London and screened them by current anti-HIV $1 / 2$ assays incorporating synthetic antigens marketed by 12 kit manufacturers.

\section{Methods}

Manufacturers of commonly used anti-HIV kits based on synthetic antigens were invited to submit kits for the evaluation. Twelve antiHIV-1/2 enzyme immunoassays (EIAs) were included (table 1).

A panel of 1092 serum specimens previously determined to be anti-HIV-1 positive was as- sembled from specimens received for routine testing by the Westminster Hospital microbiology laboratory, London. Specimens were aliquoted in volumes of about $1 \mathrm{ml}$ into the wells of high capacity 96-well microtitre plates (Beckman 071). The aliquots were stored frozen, in which state they were transported to the Virus Reference Division. They were kept there at $-20^{\circ} \mathrm{C}$ until evaluated. For the nine weeks that it took to test the specimens once by the 12 EIAs the specimens were stored at $+4^{\circ} \mathrm{C}$. No tests were repeated at this stage.

The anti-HIV status of specimens that gave a result in any of the assays discordant with that previously determined by the Westminster Hospital microbiology laboratory was further investigated by western blot (HIV Blot 2.2, Genelabs Diagnostics S.A., Geneva, Switzerland) and "in house" IgG and IgM antiHIV capture EIAs. ${ }^{34}$ In addition, new aliquots of the original specimens were sought for further testing. Each assay was used according to its manufacturer's protocol.

\section{Results}

Of the 1092 specimens originally designated anti-HIV-1 positive, $1079(98 \cdot 8 \%)$ reacted in all 12 assays. The remaining 13 each gave a negative result in one or more assays. For eight of these a fresh aliquot of specimen was available from the Westminster Hospital microbiology laboratory for repeat testing, though only two of these aliquots were sufficient in volume to be retested in all of the assays.

The 13 specimens which gave rise to negative results were categorised, A to D (table 2),

Table 2 Details of patients and HIV results for the 13 serum samples that gave rise to unexpected negative findings in anti HIV-1/2 screening assays

\begin{tabular}{|c|c|c|c|c|c|c|c|c|c|c|}
\hline \multirow[b]{2}{*}{ Specimen } & \multicolumn{6}{|c|}{ Western blot } & \multirow[b]{2}{*}{$\begin{array}{l}\text { Negative } \\
\text { assays }^{\mathrm{c}}\end{array}$} & \multirow[b]{2}{*}{ Clinical status } & \multirow[b]{2}{*}{$\begin{array}{l}\text { Exposure } \\
\text { group }\end{array}$} & \multirow[b]{2}{*}{ Comment } \\
\hline & $\begin{array}{l}\text { First } \\
\text { (gag }\end{array}$ & pol & env) & $\begin{array}{l}\text { Second } \\
\text { (gag }\end{array}$ & pol & env) & & & & \\
\hline \multicolumn{11}{|c|}{ A Specimens thought to have given rise to false negative results } \\
\hline 1. 7882 & + & - & + & NA & & & 10 & No information & Homosexual & IgM anti $\mathrm{HIV}+++$; seroconversion \\
\hline 2. 9694 & tr & $\operatorname{tr}$ & - & + & $\operatorname{tr}$ & - & 3,10 & Seroconversion illness & Not known & IgM anti $\mathrm{HIV}+++$; serovonversion \\
\hline 3. 8518 & tr & - & tr & tr & - & + & $1,4,7,8,9$ & "Known HIV positive" & Homosexual & Unreactive in 5 recombinant assays \\
\hline B Speci & mens th & ught & have be & $n$ incorrec & ctly de & znated & nti-HIV positive & & & \\
\hline 4. 2864 & - & - & - & $=$ & - & - & $2,3,5,6,8,10,11$ & No information & Homosexual & Reactive only in recombinant assays \\
\hline $\begin{array}{l}\text { 5. } 8797 \\
\text { C Speci }\end{array}$ & $\overline{\text { mens th }}$ & $\overline{u g h t}$ & - & $\underset{\text { eriorated }}{\text { NA }}$ & in sto & & $1-3,6-12$ & Asymptomatic & Homosexual & Two assays weakly reactive \\
\hline 6. 3407 & + & $\operatorname{tr}$ & + & + & + & + & $2,3,6,7,11$ & Asymptomatic & Bisexual & Stronger reactions on fresh aliquot \\
\hline 7. 8123 & + & + & tr & + & + & + & $4,8,9$ & No information & African female & Stronger reaction on a fresh aliquot \\
\hline 8. 9306 & + & + & + & + & + & + & $1,3-5,7-10$ & Asymptomatic & Homosexual & Stronger reactions on fresh aliquot \\
\hline 9. 9869 & + & + & + & NA & & & $1,3-5,7-10$ & "Known HIV positive" & Homosexual & Non-reactive in a wide range of assays \\
\hline D Nega & tive rest & ts the & ht to $h \mathrm{c}$ & ve arisen & due t & echnica & & & & \\
\hline 10. 7334 & + & + & + & NA & & & 11 & No information & IVDU & \\
\hline 11.9133 & tr & + & + & NA & & & 4 & AIDS & Homosexual & \\
\hline 12. 9534 & + & + & + & + & + & + & 4 & ARC & Homosexual & \\
\hline 13. 9904 & + & + & + & + & + & + & 1,10 & "Known HIV positive" & Homosexual & \\
\hline
\end{tabular}

a Western blot result on specimen initially archived; ${ }^{b}$ western blot results on fresh aliquot of same specimen; ${ }^{c}$ see table 1 for key to identify the EIAs; tr, trace reaction observed; NA, fresh aliquot not available; ARC, AIDS related complex; IVDU, intravenous drug user. 
according to the four possible reasons for the failure of assays to give a positive reaction (though in individual cases it cannot be certain why an apparently false negative reaction arose). The categories were:

A-Specimens that revealed true assay insensitivity. Two patients were categorised as seroconverters on the basis of their western blot profile and the presence of strong IgM anti-HIV reactivity. A third was believed to be anti-HIV positive on the basis of western blot reactivity which just met minimum criteria for positivity although some doubt remains about whether this patient was truly infected with HIV. His specimen was unreactive in five assays based mostly on "recombinant" antigens. In the test on specimens from these three patients there were eight $(0.061 \%)$ false negative results.

B-Specimens thought to have been incorrectly designated anti-HIV positive. Samples from two patients were thus categorised on the basis of western blot analysis. No clinical information was available on one patient; the other was asymptomatic.

C-Specimens thought to have deteriorated in storage. Four specimens were categorised as such on the basis of a substantial increase in the reactivity of western blot and other tests on a fresh aliquot of the same specimen. In some instances the second aliquot was of sufficient volume to be retested by those assays that had been negative and a positive reaction was obtained.

D-Specimens in which negative results were thought to be because of technical error. Five tests, on four specimens, that were initially negative were positive on repeat testing of the original specimen. This suggests that the specimen or one of the reagents had not been added to the test well, although the possibility that the solid phase was not coated with antigen during manufacture could not be ruled out.

\section{Discussion}

In this study we investigated the ability of 12 commercial anti-HIV screening assays that use synthetic HIV antigens to detect anti-HIV in 1092 specimens previously found to be antiHIV positive during routine laboratory diagnosis. There was a high degree of concordance in detecting positive specimens (almost 99\% of the positive specimens were detected by all 12 assays) and there was no difference in ability to detect anti-HIV between antigens derived from the expression of recombinant HIV DNA and oligopeptide antigens.

At first, there was at least one apparently false negative result for $13(1.2 \%)$ of the specimens previously reported as anti-HIV positive. However, subsequent testing clarified these findings and indicated that only a few of the false reactions were attributable with certainty to assay insensitivity. Other factors that were or might have been responsible for the appearance of false negativity were: (1) incorrect original designation of the specimen as positive or continuing uncertain serostatus; (2) deterioration of the specimen in storage; and (3) technical error.
If (1) and (2) are excluded as irrelevant to the issue of whether false negative results can occur in routine testing, then the false negativity rate in this study was about 1 per 1000 tests.

A number of lessons can be drawn from this study. Firstly, there is no evidence that assays based on either type of synthetic antigen, recombinant DNA coded polypeptide or synthetic oligopeptide, are consistently less sensitive though there is a suggestion, as previously shown, ${ }^{5}$ that some assays incorporating oligopeptide antigens might be marginally less sensitive at seroconversion. On the other hand, one serum in this study apparently positive on western blot analysis idiosyncratically failed to react in five of the seven assays that incorporated antigens derived from recombinant DNA; one of the other two "recombinant" assays blended oligopeptide with recombinant antigens. Secondly, our study suggests that technical errors may be responsible for as many false negative results as intrinsic assay failures. Thirdly, it should be noted that specimens collected during seroconversion may give rise to negative but, nevertheless, often elevated optical density values. Thus, a "high" negative result in a patient known to be at increased risk should prompt further investigation and, if possible, a request for a follow up specimen. A specimen taken at an interval of a week or more from a subject undergoing seroconversion will usually display positive reactivity. Fourthly, long term storage of specimens at a nominal temperature no lower than $-20^{\circ} \mathrm{C}$ and the need to hold serum samples for several weeks at $4^{\circ} \mathrm{C}$ during EIA testing, as in this study, may lead to loss of anti-HIV reactivity: fewer false negative results might be expected with fresh specimens such as are routinely tested in clinical and transfusion laboratories. When specimens are stored, regular checks must be made to ensure that freezer temperatures have not risen above $-20^{\circ} \mathrm{C}$.

In spite of the false negative results and technical errors that were identified in this study, $99 \%$ of the positive specimens were antiHIV reactive by all of the 12 assays. Although their performances may have fallen short of perfection, we conclude that all the assays are sufficiently sensitive for use as screening tests in the population from which these specimens were drawn. However, as our study population was entirely London based and predominantly composed of homosexual men, our results do not rule out the possibility of a higher false negative rate in other locations and risk groups. For these, the restricted number of epitopes represented by HIV antigens synthesised in European and North American laboratories might not always react with antibodies elicited by heterogeneous strains of HIV. ${ }^{6}$

We thank Sweenie Goonesekera and Jay Gandhi for technica help and the Medical Devices Directorate of the UK Department of Health for financial support.

1 Lelie PN, Reesink HW, Huisman JG. Earlier detection of HIV and second generation antibody assays. Lancet 1987 ii:343.

2 Constantine N. Serologic tests for the retroviruses: approaching a decade of evolution. AIDS 1993;7:1-13. 
3 Lange JMA, Parry JV, de Wolf F, Mortimer PP, Goudsmit J. Diagnostic value of specific IgM antibodies in primary HIV infection. AIDS 1988;2:31-5.

4 Connell JA, Parry JV. Detection of anti-HIV in saliva and urine at the time of seroconversion. Clinical and Diagnostic urine at the time of serocon
Virology 1994;1:299-311.
5 McAlpine L, Gandhi J, Parry JV, Mortimer PP. Thirteen current anti-HIV-1/HIV-2 enzyme immunoassays: how accurate are they? $\mathcal{F}$ Med Virol 1994;42:115-18.

6 Loussert-Ajaka I, Ly TD, Chaix MI, Ingrand D, Saragosti S, Courouce AM, et al. HIV-1/HIV-2 seronegativity in HIV1 subtype $O$ infected patients. Lancet 1994;343:1939-4.

\title{
Anticomplementary activity in serum samples from patients with acute parvovirus B19 infection
}

\author{
S A Barton, J Q Nash, J Jones, M Sillis, B J Cohen
}

\begin{abstract}
Of 65 serum samples submitted for diagnostic purposes which proved to be anticomplementary by complement fixation test, 49 were parvovirus B19 IgM positive. Forty four of the 49 serum samples were from patients with arthropathy. Acute parvovirus B19 infection should be suspected when a patient has symptoms of disease of the joints and the serum is anticomplementary.

(f Clin Pathol 1995;48:493-494)
\end{abstract}

Keywords: Parvovirus B19, immune complexes, arthropathy.

The complement fixation test (CFT) utilises the failure of complement induced lysis of sensitised red blood cells to detect immune complexes formed by the addition of a laboratory "test" antigen to a patient's serum containing specific antibody. CFT remains a widely used method for diagnosing viral and bacterial infections, but preformed immune complexes in a patient's serum may cause an "anticomplementary" effect in serum to which no "test" antigen has been added and render the test indeterminate.

We wish to report that this anticomplementary effect is frequently encountered in acute parvovirus B19 infection. Infection with parvovirus B19 has a spectrum of clinical manifestations and it is likely that the full range of parvovirus B19 disease is still to be resolved. ${ }^{1}$ The reticular rash and acute polyarthralgia associated with parvovirus B19 infection are thought to be precipitated by immune complex deposition. ${ }^{2}$ Adult polyarthropathy resulting from parvovirus B19 is easily confused with other symmetrical polyarthropathies.

\section{Methods}

Over 15 months, Ashford Public Health Laboratory received 88 serum samples which proved to be anticomplementary during routine CFT examination. To date 43 of these unselected specimens have been examined retro- spectively for evidence of parvovirus B19 infection. Twenty two anticomplementary serum samples from Norwich Public Health Laboratory (selected from patients with symptoms suggestive of parvovirus B19 infection) were also tested. Sequential serum samples from the same patient were often not anticomplementary after a period of two to three weeks.

\section{Results}

Twenty seven of the 43 Ashford serum samples and all 22 Norwich serum samples were parvovirus B19 IgM positive by IgM capture radioimmunoassay. ${ }^{3}$ All of the samples were parvovirus B19 DNA negative by dot blot hybridisation assay. ${ }^{4}$ One of the 23 positive Ashford and two of the 22 positive Norwich serum samples were also positive for rheumatoid factor. The two rheumatoid factor positive Norwich serum samples were also weakly positive for rubella IgM.

\section{Discussion}

The higher proportion of positive results for parvovirus B19 IgM in the Norwich serum samples is probably explained by the fact that they were preselected from patients with symptoms suggestive of parvovirus B19 infection. All had joint involvement and their mean age was 36 years. ${ }^{5}$ Of the 27 of 43 parvovirus B19 IgM positive Ashford serum samples, 22 were from patients with joint involvement (mean age 39 years) but only one of 16 of the parvovirus B19 IgM negative samples were from patients with joint symptoms.

The presence of circulating immune complexes is a feature of parvovirus infections in humans and animals as exemplified by the severe immune complex glomerulonephritis of Aleutian disease in mink. ${ }^{6}$ It is of interest that one of the parvovirus B19 IgM positive patients from Ashford also had glomerulonephritis confirmed by biopsy.

Clinical and laboratory staff should suspect acute parvovirus B19 infection when serum from an adult patient with joint symptoms is 